\title{
Health care seeking behaviour of mothers towards diarrheal disease of children less than 5 years in Mekelle city, North Ethiopia
}

Tedros Fissehaye ${ }^{1 *}$, Ashenafi Damte ${ }^{2}$, Atsede Fantahun ${ }^{2}$ and Kahsu Gebrekirstos ${ }^{2}$

\begin{abstract}
Objective: To assess the health care seeking behavior of mothers on diarrheal disease of under five children and associated factors in Mekelle City, Northern Ethiopia.

Result: This study revealed that $72.5 \%(n=58)$ of the mothers who reported their children had diarrhea had sought health care facilities. Three quarter, (75.9\%) of them was seeking health in the public health care facility. Majority, $89.3 \%$ of those children who had severe diarrhea sought at health care facilities. In the multivariable analysis, severity of diarrhea ( $P=0.04$ ) and blood in stool) were the significantly associated factors with health seeking behavior of mothers for childhood diarrhea.
\end{abstract}

Keywords: Health care, Children, Diarrhea, Seeking behavior, Mother

\section{Introduction}

Diarrhea is defined as having loose or watery stools at least three times a day, or increased frequency of stool as reported by the mother [1]. Although most childhood diarrhea episodes are mild, acute cases can lead to death or other severe consequences as a result of severe fluid loss and dehydration [1].

Globally, childhood diarrhea is among the main killers of children under the age of 5 years [2]. In 2015, 9\% of deaths of children under age 5 years are caused by diarrheal disease alone [2]. Most of child deaths from diarrhea occur in the low-income regions of the world in which nearly $90 \%$ of the deaths occur in sub-Saharan Africa and South Asia [3]. As a result, child hood diarrhea has long been regarded as a disease of poverty because it is mainly associated with factors such as, under nutrition and lack of access to essential services such as toilets and clean water [4].

Children are dying because services are provided piecemeal and those most at risk are not being reached. For

\footnotetext{
*Correspondence: teddypedi@gmail.com

${ }^{1}$ Ayder Comprehensive Referral Hospital, Mekelle University, Mekelle, Ethiopia

Full list of author information is available at the end of the article
}

instance, children are not receiving life-saving treatment, and only $35 \%$ of children with diarrhea receive oral rehydration therapy [3]. United Nations Children's Fund (UNICEF) recommended combination of oral rehydration salts (ORS) and zinc supplementation can reduce the severity of diarrhea while preventing relapse and dehydration [4]. Coverage of zinc supplementation for diarrhea treatment is particularly low because introduction and scale-up in most low- and middle-income countries has only occurred recently [2].

Deaths due to these diseases are largely preventable through optimal breastfeeding practices and adequate nutrition, vaccinations, hand washing, safe drinking water and basic sanitation, among other measures. Since 1990, Ethiopia has shown a remarkable reduction in under five mortality and the country is one of the few countries that has achieved the millennium development goal 4 (MDG 4) of reducing child deaths by two thirds [5]. Ending preventable childhood deaths and consequences is possible through proven cost-effective preventive and curative interventions and does not demand advanced technology. Unfortunately, there is a gap in coverage of relevant and effective interventions and has not yet reached the levels required for the desired

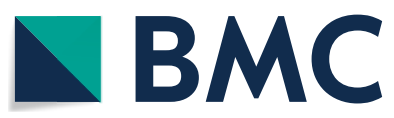

C The Author(s) 2018. This article is distributed under the terms of the Creative Commons Attribution 4.0 International License (http://creativecommons.org/licenses/by/4.0/), which permits unrestricted use, distribution, and reproduction in any medium, provided you give appropriate credit to the original author(s) and the source, provide a link to the Creative Commons license, and indicate if changes were made. The Creative Commons Public Domain Dedication waiver (http://creativecommons.org/ publicdomain/zero/1.0/) applies to the data made available in this article, unless otherwise stated. 
impact. Improvements in drinking water, sanitation and hygiene are reducing diarrheal infections, but only two in five children in the world get appropriate treatment when they fall ill [2].

Through the support from UNICEF and other partners, the government of Ethiopia has also been working to strengthen the integrated community case management (ICCM) of diarrhea, malaria and pneumonia. Yet, coverage of these treatments is unacceptably low only $2 \%$ and $26 \%$ of children receive zinc and ORS, respectively. In general, delayed treatment-seeking behavior and low utilization of health services are key bottlenecks to treating children under five [5]. Improving access to treatment for diarrhea can help dramatically reduce under 5 years deaths in Ethiopia. Improving and optimizing care seeking behaviors and thereby increasing utilization of ICCM and IMNCI treatment services for pneumonia and diarrhea [5].

Yet, the knowledge about how and when families seek treatment for these childhood diarrheal illnesses are not well known and utilization of HEWs at the health post for child illness has been found to be very low. Little is known about reasons for low utilization of health care services and care seeking behaviors for this population [6]. Therefore, this study with fill the gap by providing information on mother's health care seeking behavior and its determinants.

\section{Main text Methods}

This community based cross-sectional study was conducted in Mekelle City, Tigray regional state, Northern Ethiopia from March 2015 to June, 2016. All mothers who have under five children in Mekelle city were the source population and selected mothers were the study population. A multi-stage sampling technique was used to select 540 mothers. Four weredas (Districts) were selected using lottery method and ketenes (Sub districts) was selected from the selected wereda randomly and number of households hold under five children was taken from health extension workers and sampling frame was made from it. Then systematic sampling technique was employed for household's selection from each kebeles. The data was collected using structured interviewer administered questionnaires adapted from the World Health Organization (WHO) generic protocol for a community-based survey on utilization of health care service for gastroenteritis [7]. Four nurses and two B.Sc. nurses were recruited for data collection and supervision respectively. After data collection, each questionnaire was checked for completeness and the data was edited, coded, entered, cleaned and analyzed using SPSS for windows version 20. Descriptive statistics was computed to determine health seeking behavior as well as binary and multiple logistic regression analysis was performed to assess the relationship between dependent and independent variables. The degree of association between independent and dependent variables was assessed using odds ratio with 95\% confidence interval or with respective to P-value $<0.05$. Efforts were made to assess whether the necessary assumptions for the application of multiple logistic regression were fulfilled. In this regard, in the final model, the Omnibus test of model coefficients had a Chi square value of 23.80 and a probability of $\mathrm{P}=0.022$, and Hosmer Lemeshow had Chi square value of 12.74 with a significance of 0.121 and therefore the model is good fit model. Finally, the results of study components were presented using texts, graphs and tables.

\section{Result}

\section{Socio-demographic characteristics}

In this study, a total of 540 mothers whose children aged under five (0-59 months) were participated making the response rate of $100 \%$. The median (IQ range) of age of the mothers was $29( \pm 6)$ years with more than half, $301(55.70 \%)$ of them were found between age range of $20-29$ years. Four hundred sixty-six $(86.30 \%)$ of mothers were Orthodox Christianity by religion. Regarding the educational status of mothers, $483(89.40 \%)$ of them had attended formal education and out of them 179 (33.10\%) had accomplished diploma and higher institution. Majority, 517 (95.70\%) of mothers were married, 263 (48.7\%) house wife by occupation. The average (median) monthly household income of the study participants was 2700 $( \pm 2000)$ Ethiopian Birr, in which one third, 160 (29.60\%) of them had monthly income ranged 1001-2000 Ethiopian Birr (Table 1).

\section{Magnitude and care seeking behavior of childhood diarrhea}

From the total 540 under five children, there were 80 (14.81\%) children who experienced diarrhea. Out of these $20(3.7 \%)$ of them had a diarrhea of 2 weeks or longer duration. The most common symptoms reported was increased thirst $48(60.0 \%)$ followed by irritability 44 (55.0\%), and decreased fluid intake 43 (53.8\%). This study found that $58(72.5 \%)$ of mothers were reported seeking care at health care facilities (both public and private). Health center was the common public health facility where mothers took their children to seek health care (Table 2).

This study also revealed that 25 (89.3\%) children who had severe diarrhea sought at health facility. Among all 
Table 1 Socio-demographic characteristics of the respondents in Mekelle City, Ethiopia 2016 ( $n=540)$

\begin{tabular}{|c|c|c|c|}
\hline Variables & Category & Frequency & Percentage (\%) \\
\hline \multirow{4}{*}{$\begin{array}{l}\text { Age of the child in } \\
\text { months }\end{array}$} & $<6$ & 56 & 10.4 \\
\hline & $6-11$ & 69 & 12.8 \\
\hline & $12-23$ & 133 & 24.6 \\
\hline & $24-59$ & 282 & 52.2 \\
\hline \multirow{6}{*}{$\begin{array}{l}\text { Mothers'age in } \\
\text { years }\end{array}$} & $\leq 19$ & 1 & 2 \\
\hline & $20-24$ & 58 & 10.7 \\
\hline & $25-29$ & 243 & 45.0 \\
\hline & $30-34$ & 163 & 30.2 \\
\hline & $35-39$ & 62 & 11.5 \\
\hline & $\geq 40$ & 13 & 2.4 \\
\hline \multirow[t]{4}{*}{ Religion } & Orthodox & 466 & 86.3 \\
\hline & Muslim & 63 & 11.7 \\
\hline & Protestant & 8 & 1.5 \\
\hline & Catholic & 3 & 0.6 \\
\hline \multirow[t]{4}{*}{ Marital status } & Single & 4 & 0.7 \\
\hline & Married & 517 & 95.7 \\
\hline & Divorced & 16 & 3.0 \\
\hline & Widowed & 3 & 0.6 \\
\hline \multirow[t]{4}{*}{ Educational Status } & Formal education & 57 & 10.6 \\
\hline & Elementary school & 137 & 25.4 \\
\hline & Secondary school & 167 & 30.9 \\
\hline & Diploma and above & 179 & 29.1 \\
\hline \multirow{7}{*}{$\begin{array}{l}\text { Occupation of } \\
\text { mother }\end{array}$} & House wife & 263 & 48.7 \\
\hline & Farmer & 7 & 1.3 \\
\hline & Civil servant & 121 & 22.4 \\
\hline & Private & 92 & 17.0 \\
\hline & Student & 10 & 1.9 \\
\hline & Merchant & 46 & 8.5 \\
\hline & Other & 1 & 0.2 \\
\hline \multirow{6}{*}{$\begin{array}{l}\text { Occupation of } \\
\text { father }\end{array}$} & Farmer & 10 & 1.9 \\
\hline & Civil servant & 158 & 29.3 \\
\hline & Private & 101 & 18.7 \\
\hline & Retired & 4 & 0.7 \\
\hline & Trader & 146 & 27.0 \\
\hline & Other $^{\mathrm{a}}$ & 121 & 22.4 \\
\hline \multirow{6}{*}{$\begin{array}{l}\text { Average monthly } \\
\text { income in Ethio- } \\
\text { pian Birr }\end{array}$} & $<1000$ & 71 & 13.1 \\
\hline & $1001-2000$ & 160 & 29.6 \\
\hline & $2001-3000$ & 142 & 26.3 \\
\hline & $3001-4000$ & 62 & 11.5 \\
\hline & $4001-5000$ & 55 & 10.2 \\
\hline & $>5000$ & 50 & 9.3 \\
\hline
\end{tabular}

a Daily laborer, construction, Broker

children with diarrhea, 69 (86.3\%) of them had received oral rehydration salt (ORS) both at home and at health facility. Fifteen (18.8\%) of mothers had also reported that as their children were admitted to hospitals.
Table 2 Occurrence and health care seeking behavior of childhood diarrhea in Mekelle City, Tigray, Ethiopia, $2016(n=540)$

\begin{tabular}{|c|c|c|c|}
\hline Variables & Category & Frequency & Percent \\
\hline \multirow[t]{2}{*}{ Presence of diarrhea } & Yes & 80 & 14.8 \\
\hline & No & 460 & 85.2 \\
\hline \multirow[t]{3}{*}{ Severity of diarrhea } & Mild & 18 & 3.3 \\
\hline & Moderate & 34 & 6.3 \\
\hline & Severe & 28 & 5.2 \\
\hline \multirow{2}{*}{$\begin{array}{l}\text { Duration of diarrhea } \\
\text { (weeks) }\end{array}$} & $<2$ & 20 & 25 \\
\hline & $\geq 2$ & 60 & 75 \\
\hline \multirow[t]{7}{*}{ Clinical manifestation $^{a}$} & Increased thirsty & 48 & 60 \\
\hline & Irritability & 44 & 55 \\
\hline & Decreased fluid intake & 43 & 53 \\
\hline & Lethargic & 41 & 51.3 \\
\hline & Sunken eye & 39 & 48.8 \\
\hline & Blood in stool & 8 & 10 \\
\hline & Others & 14 & 17.5 \\
\hline \multirow{6}{*}{$\begin{array}{l}\text { Measures taken for } \\
\text { sickness }\end{array}$} & Health facilities & 58 & 72.5 \\
\hline & Pharmacy & 7 & 8.8 \\
\hline & Home remedies & 6 & 7.5 \\
\hline & Traditional healer & 3 & 3.8 \\
\hline & No action & 2 & 2.5 \\
\hline & Others & 4 & 5 \\
\hline \multirow[t]{2}{*}{ Type of facility } & Public health facility & 44 & 75.9 \\
\hline & Private health facility & 14 & 24.1 \\
\hline \multirow{2}{*}{$\begin{array}{l}\text { Type of public health } \\
\text { facility }\end{array}$} & Health center & 34 & 77.3 \\
\hline & Hospital & 10 & 22.7 \\
\hline \multirow[t]{2}{*}{ ORS given } & Yes & 69 & 86.3 \\
\hline & No & 11 & 13.7 \\
\hline
\end{tabular}

a More than one answer was possible

Factors associated with mother's health seeking behavior Mother's health seeking behavior was assessed for its association with Socio demographic, health service, illness characteristics as well as by way of traditional practices. The bivariate analysis model showed that severity of the illness (diarrhea) was significantly associated with the health seeking behavior of mothers $(P=0.008)$. In the multivariable analysis, adjusting possible confounding variables, severity $(\mathrm{P}=0.04)$ and blood in stool $[\mathrm{AOR}=0.13 ; 95 \% \mathrm{CI}(0.02,0.88)]$ were the significantly associated factors with health seeking behavior of mothers for the childhood diarrhea. On the other hand, child age, number of under five children, educational status, monthly household income, availability of transportation, persistency of diarrhea and other characteristics of the illness were not significant factors in this study (Table 3). 
Table 3 Factors associated with mothers' health care seeking behavior towards childhood diarrhea in Mekelle city, North Ethiopia 2016

\begin{tabular}{|c|c|c|c|c|}
\hline \multirow[t]{2}{*}{ Variables } & \multicolumn{4}{|c|}{ Seeking structured health care facility } \\
\hline & No & Yes & COR & AOR \\
\hline \multicolumn{5}{|c|}{ Child age in months } \\
\hline$<6$ & $3(42.9 \%)$ & $4(57.1 \%)$ & $0.552[0.11,2.85]$ & - \\
\hline $6-11$ & $1(16.7 \%)$ & $5(83.3 \%)$ & $2.07[0.22,19.63]$ & - \\
\hline $12-23$ & $6(23.1 \%)$ & $20(76.9 \%)$ & $1.38[0.44,4.29]$ & - \\
\hline $24-59$ & $12(29.3 \%)$ & $29(70.7 \%)$ & 1 & \\
\hline \multicolumn{5}{|l|}{ Marital status } \\
\hline Married & $20(26.3 \%)$ & $56(73.7 \%)$ & 1 & \\
\hline Unmarried & $2(50.0 \%$ & $2(50.0 \%)$ & $0.356[0.047,2.71]$ & $0.24[0.01,11.53]$ \\
\hline \multicolumn{5}{|l|}{ Occupation } \\
\hline Housewife & $13(37.1 \%)$ & $22(62.9 \%)$ & 1 & \\
\hline Civil servant & $3(16.7 \%)$ & $15(83.3 \%)$ & $2.96[0.72,12.18]$ & - \\
\hline Private & $6(23.1 \%)$ & $20(76.9 \%)$ & $1.97[0.63,6.17]$ & - \\
\hline Other & $0(0.0 \%)$ & $1(100.0 \%)$ & $9.5 \mathrm{E} 8[0.000,-]$ & - \\
\hline \multicolumn{5}{|c|}{ Educational status } \\
\hline Illiterates & $2(25.0 \%)$ & $6(75.0 \%)$ & 1 & \\
\hline Literate & $20(27.8 \%)$ & $52(72.2 \%)$ & $0.867[0.161,4.66]$ & - \\
\hline \multicolumn{5}{|c|}{ Number of under five children } \\
\hline 1 child & $13(26.0 \%)$ & 37 (74.0\%) & 1 & \\
\hline 2 or more & $9(30.0 \%)$ & $21(70.0 \%)$ & $0.820[0.30,2.24]$ & - \\
\hline \multicolumn{5}{|l|}{ Age of mother } \\
\hline$<30$ & $12(26.7 \%)$ & $33(73.3 \%)$ & 1 & \\
\hline $30-39$ & $9(28.1 \%)$ & $23(71.9 \%)$ & $0.93[0.34,2.56]$ & - \\
\hline$\geq 40$ & $1(33.3 \%)$ & $2(66.7 \%)$ & $0.73[0.60,8.77]$ & - \\
\hline \multicolumn{5}{|l|}{ Sex of the child } \\
\hline Male & $13(26.5 \%)$ & $36(73.5 \%)$ & 1 & \\
\hline Female & $9(29.0 \%)$ & $22(71.0 \%)$ & $0.883[0.32,2.404]$ & - \\
\hline \multicolumn{5}{|c|}{ Presence of television } \\
\hline No & $3(60.0 \%)$ & $2(40.0 \%)$ & 1 & \\
\hline Yes & $19(25.3 \%)$ & $56(74.7 \%)$ & $4.421[0.68,28.5]$ & $4.96[0.43,57.39]$ \\
\hline \multicolumn{5}{|c|}{ Presence of vehicle (car) } \\
\hline No & $19(27.1 \%)$ & $51(72.9 \%)$ & 1 & \\
\hline Yes & $3(30.0 \%)$ & $7(70.0 \%)$ & $0.87[0.204,3.71]$ & - \\
\hline \multicolumn{5}{|l|}{ Increased thirst } \\
\hline No & $9(28.1 \%)$ & $23(71.9 \%)$ & 1 & \\
\hline Yes & $13(27.1 \%)$ & 35 (72.9\%) & $1.054[0.388,2.86]$ & - \\
\hline \multicolumn{5}{|l|}{ Irritability } \\
\hline No & $12(33.3 \%)$ & $24(66.7 \%)$ & 1 & \\
\hline Yes & $10(22.7 \%)$ & $34(77.3 \%)$ & $1.70[0.63,4.57]$ & $1.24[0.27,5.59]$ \\
\hline \multicolumn{5}{|c|}{ Decreased fluid intake } \\
\hline No & $13(35.1 \%)$ & 24 (64.9\%) & 1 & \\
\hline Yes & $9(20.9 \%)$ & 34 (79.1\%) & $2.05[0.76,5.55]$ & $0.73[0.17,3.10]$ \\
\hline \multicolumn{5}{|l|}{ Lethargy } \\
\hline No & $13(33.3 \%)$ & $26(66.7 \%)$ & 1 & \\
\hline Yes & $9(22.0 \%)$ & $32(78.0 \%)$ & $1.78[0.66,4.809]$ & $0.50[0.10,2.58]$ \\
\hline
\end{tabular}


Table 3 (continued)

\begin{tabular}{|c|c|c|c|c|}
\hline \multirow[t]{2}{*}{ Variables } & \multicolumn{4}{|c|}{ Seeking structured health care facility } \\
\hline & No & Yes & COR & AOR \\
\hline \multicolumn{5}{|l|}{ Sunken eye } \\
\hline No & $14(34.1 \%)$ & 27 (65.9\%) & 1 & \\
\hline Yes & $8(20.5 \%)$ & $31(79.5 \%)$ & $2.009[0.73,5.52]$ & $0.55[0.10,3.01]$ \\
\hline \multicolumn{5}{|c|}{ Blood in stool } \\
\hline No & $18(25.0 \%)$ & $54(75.0 \%)$ & 1 & \\
\hline Yes & $4(50.0 \%)$ & $4(50.0 \%)$ & $0.333[0.75,1.47]$ & $0.13[0.02,0.88]$ \\
\hline \multicolumn{5}{|c|}{ Persistency of diarrhea } \\
\hline No & $17(28.3 \%)$ & $43(71.7 \%)$ & 1 & \\
\hline Yes & $5(25.0 \%)$ & $15(75.0 \%)$ & $1.19[0.373,3.77]$ & - \\
\hline \multicolumn{5}{|c|}{ Severity of diarrhea } \\
\hline Mild & $10(55.6 \%)$ & $8(44.4 \%)$ & 1 & \\
\hline Moderate & $9(26.5 \%)$ & $25(73.5 \%)$ & $3.47[1.044,11.6]$ & $9.55[1.11,81.74]$ \\
\hline Severe & $3(10.7 \%)$ & $25(89.3 \%)$ & $10.42[2.29,47.44]$ & $44.6[2.23,893.2]$ \\
\hline \multicolumn{5}{|c|}{ Previous admission history } \\
\hline No & $20(30.8 \%)$ & $45(69.2 \%)$ & 1 & \\
\hline Yes & $2(13.3 \%)$ & 13 (86.7\%) & $2.89[0.59,14.013]$ & $5.41[0.52,56.39]$ \\
\hline \multicolumn{5}{|c|}{ Kind of available transportation } \\
\hline Foot step & $14(35.0 \%)$ & $26(65.0 \%)$ & 1 & \\
\hline Taxi & $6(20.7 \%)$ & $23(79.3 \%)$ & $2.064[0.68,6.26]$ & $1.65[0.43,6.40]$ \\
\hline Bajaj & $2(18.2 \%)$ & $9(81.8 \%)$ & $2.423[0.46,12.79]$ & $1.68[0.21,13.20]$ \\
\hline
\end{tabular}

\section{Discussion}

This study was primarily aimed to assess the health care seeking behavior of mothers on diarrheal disease of under 5 years children in Mekelle city to help to improve the health care seeking behavior of mothers for the emergence of diarrhea.

In this study, it was found that from 540 of the total households, childhood diarrheal illness was reported by $80(14.81 \%)$ within 01 months recall period. This is similar with period prevalence reported from studies conducted earlier in Mekelle, Tigray Ethiopia (16.4\%) [8] And in Urban Slum of Delhi, India which was $14.8 \%$ [9]. But it is lower than the period prevalence reported from the studies conducted earlier in West Shoa, Ethiopia $(22.1 \%)$, Sierra Leone (25.6\%), rural Niger $(36.8 \%)$ and it is higher as compared to the findings from studies conducted in Mirzapur, rural Bangladesh, which was 7.4\% [8-13]. The difference in the reported period prevalence of diarrhea might be due to the difference in geographic, seasonal variation and socioeconomic conditions.

This study revealed that $72.5 \%(n=58)$ of the mothers who reported their children had diarrhea had sought health care facilities. More or less, similar report was made by studies carried out in West Shoa, Ethiopia (69.3\%), Central Ethiopia (77.0\%) and Rural Niger (70.4\%). But it is lower that study findings from Serra Leone, which was 85\% [11-14]. This study also showed that $89.5 \%$ of those children who had severe diarrhea had sought the health facility which is similar with the findings done from rural Niger, which was $83.8 \%$ [12]. This might be an indicator of as mothers are being heath seeker while their child is seriously ill.

This study found that all mothers $100 \%(n=58)$ who reported that they sought health care facilities have taken their children to the health facilities within $1-72 \mathrm{~h}$ which is higher than the result finding from west Shoa, Ethiopia, which was $83.2 \%$ [13]. This difference might be due to the reason that these mothers were good in seeking of health on perspective of time because most of them tended to act and brought their sick children with in short period of time.

The study also found that $2.5 \%$ of the mothers whose child had diarrhea reported that they did not take any action for the sickness. This is slightly lower with the findings from west Shoa, Ethiopia (4.3\%) and urban slum of Delhi, India $(5.8 \%)[8,13]$. This may be due to the present improvement in awareness about the causes and treatments as well as the positive perceived severity that exist about childhood diarrhea.

In the binary logistic regression model association test was done to identify the determinant factors of mothers' health seeking behavior for childhood 
diarrhea. In this study, severity of diarrhea was a significant predictor of health seeking behavior of mothers $(P=0.04)$. This is consistent with the findings conducted in rural Niger [11].

\section{Conclusion}

This study revealed that nearly three quarter of mothers were health care seekers for if their under-five child had diarrhea. However, a significant number of mothers were treated the childhood diarrhea out of health care settings. Increased thirst, irritability, and decreased fluid intake were the most common symptoms reported. This study also showed that there is a diversity of perception on the causes and treatment options of child hood diarrhea. Severity of diarrhea and blood in stool were the independent determinant factors for health care seeking behavior of mothers in the multivariable analysis.

\section{Limitations}

- The study was employed using interviewer administrated questionnaire that might result social desirability bias.

- Qualitative study is not included in the which was ideal $\mathrm{o}$ assess additional factors.

\begin{abstract}
Abbreviations
AOR: adjusted odds ratio; HEWs: health extension workers; ICCM: integrated community case management; IMNCl: integrated management of neonatal and childhood illness; MDG: millennium development goal; ORS: oral rehydration salt; UNICEF: United Nations Children Emergency Fund; WHO: World Health Organization.
\end{abstract}

\section{Authors' contributions}

TF was the principal investigator of the study; made substantial contributions in conception selecting design, data collection as well as analysis and interpretation of data. AF and AD was the supervisors of the research; participated in designing and managing data collection and analysis. KG involved in drafting and revising critically the manuscript. All authors also agreed to be accountable for all aspects of the work in ensuring that questions related to the accuracy or integrity of any part of the work are appropriately investigated and resolved. All authors read and approved the final manuscript.

\section{Author details}

${ }^{1}$ Ayder Comprehensive Referral Hospital, Mekelle University, Mekelle, Ethiopia. ${ }^{2}$ Department of Nursing, College of Health Sciences, Mekelle University, Mekelle, Ethiopia.

\section{Acknowledgements}

First and foremost, I am thankful to Mekelle University, College of Health Sciences, Department of Nursing and Ayder comprehensive specialized Hospital. I am also grateful to Mekelle city administration and respective weredas, ketenas, where the data collections undergone, for providing me the necessary information and cooperative support. My deepest gratitude also goes to the data collectors, supervisors and respondents without whom this thesis would not be realized.

\section{Competing interests}

The authors declared that they have no competing interests.

\section{Availability of data and materials}

The data is presented in the main manuscript.

\section{Consent for publication}

Not applicable.

\section{Ethics approval and consent to participate}

Ethical clearance was obtained from Mekelle University, College of Health Science Ethical Review Board. Support letter was obtained from Mekelle University to Tigray Regional Health Bureau and from Tigray Regional Health Bureau to the respective weredas and ketenas. In addition, informed consent was obtained from study participants to confirm willingness for participation after explaining the objective of the study. The information provided by each respondent was kept confidential.

\section{Funding source}

The authors declare that no funding source for this study.

\section{Publisher's Note}

Springer Nature remains neutral with regard to jurisdictional claims in published maps and institutional affiliations.

Received: 27 July 2018 Accepted: 12 October 2018

Published online: 22 October 2018

\section{References}

1. World Health Organization. Why children are still dying and what can be done. Geneva: World Health Organization; 2009.

2. United Nations International Children's Emergency Fund. Committing to child survival: a promise renewed progress report. New York: United Nations Children's Fund; 2015.

3. United Nations Children's Fund-World Health Organization. End preventable deaths: global action plan for prevention and control of pneumonia and diarrhoea by 2025. New York: United Nations Children's Fund; 2013.

4. United Nations Children's Fund. Pneumonia and diarrhoea; tackling the deadliest diseases for the world's poorest children. New York: United Nations Plaza; 2012

5. Initiative Clinton Health Access. Financing diarrhea and pneumonia treatment gaps: reducing childhood deaths from diarrhea and pneumonia proposal for a large-scale integrated approach to scale-up. New York: United Nations Children's Fund; 2013.

6. Management Sciences for Health. Strategy to increase access to treatment of childhood diarrhea, malaria and pneumonia in Ethiopia. USA: MSH; 2012.

7. World Health Organization. Generic protocols for a community-based survey on utilization of healthcare services for gastroenteritis in children. Geneva: World Health Organization Department of Vaccines and Biologicals. http://www.who.int/vaccines-documents. Accessed Nov 2002.

8. Berhe KK, Hagos M, Ayele AD, Abera GB, Tuppal CP, Kahsay HB. Assessment of mothers' health care seeking behaviors and associated factors on common childhood illnesses in Mekelle City. Trans Praxes Promot Prevent Care. 2013;3:438-44.

9. Das SK, Nasrin D, Ahmed S, et al. Health care-seeking behavior for childhood diarrhea in Mirzapur, Rural Bangladesh. Am J Trop Med Hyg. 2013;89(1):62-8.

10. Basa S. Prevalence of diarrhoea among under-five children and health seeking behavior of their mothers in an Urban Slum of Delhi. Asian J Biomed Pharm Sci. 2015;5(45):08-11.

11. Diaz T, George AS, Rao SR, et al. Healthcare seeking for diarrhoea, malaria and pneumonia among children in four poor rural districts in Sierra Leone in the context of free health care: results of a cross-sectional survey. BMC Public Health. 2013;13:157. 
12. Page AL, Hustache S, Luquero FJ, et al. Health care seeking behavior for diarrhea in children under 5 in rural Niger: results of a cross sectional survey. BMC Public Health, 2011;11:389. http://www.biomedcentral. com/1471-2458/11/389.

13. Dengia T. Mother's perception and treatment seeking behaviour for childhood diarrhea in Dendi district, west Shoa, Ethiopia. GJMEDPH. 2014;3(3):1-9.
14. Mukiira C, Ibisomi L. Health care-seeking practices of caregivers of underfive children with diarrheal diseases in two informal settlements in Nairobi, Kenya. wiredspace.wits.ac.za/.../carol\%20Mukiir. Accessed 10 Jan 2016.
Ready to submit your research? Choose BMC and benefit from:

- fast, convenient online submission

- thorough peer review by experienced researchers in your field

- rapid publication on acceptance

- support for research data, including large and complex data types

- gold Open Access which fosters wider collaboration and increased citations

- maximum visibility for your research: over $100 \mathrm{M}$ website views per year

At BMC, research is always in progress.

Learn more biomedcentral.com/submissions 